\title{
Long-Term Resveratrol Supplementation as a Secondary Prophylaxis for Stroke
}

\author{
Katalin Fodor, ${ }^{1}$ Delia Mirela Tit $\left(\mathbb{D},{ }^{1}\right.$ Bianca Pasca $\left(\mathbb{D},{ }^{1}\right.$ Cristiana Bustea $\left(\mathbb{D},{ }^{2}\right.$ \\ Diana Uivarosan $\mathbb{D D}^{2}$ Laura Endres $(\mathbb{D})^{2}$ Ciprian Iovan, ${ }^{2}$ Mohamed M. Abdel-Daim $\left(\mathbb{D},{ }^{3,4}\right.$ \\ and Simona Bungau $\mathbb{D}^{1}$ \\ ${ }^{1}$ Pharmacy Department, Faculty of Medicine and Pharmacy, University of Oradea, 410028 Oradea, Romania \\ ${ }^{2}$ Preclinical Disciplines Department, Faculty of Medicine and Pharmacy, University of Oradea, 410028 Oradea, Romania \\ ${ }^{3}$ Pharmacology Department, Faculty of Veterinary Medicine, Suez Canal University, Ismailia 41522, Egypt \\ ${ }^{4}$ Department of Ophthalmology and Micro-technology, Yokohama City University, Yokohama, Japan
}

Correspondence should be addressed to Delia Mirela Tit; mirela_tit@yahoo.com

Received 18 December 2017; Revised 28 January 2018; Accepted 5 February 2018; Published 18 March 2018

Academic Editor: Mohammad A. Kamal

Copyright ( $) 2018$ Katalin Fodor et al. This is an open access article distributed under the Creative Commons Attribution License, which permits unrestricted use, distribution, and reproduction in any medium, provided the original work is properly cited.

\begin{abstract}
Stroke is a leading cause of mortality worldwide, as well as a source of long-term disabilities and huge socioeconomic costs. This study investigates the effects of resveratrol, an antioxidant supplement, on blood pressure, weight status, glucose, and lipid profile in patients who had a stroke in the last 12 months. Two hundred and twenty-eight patients were divided into three groups: group I received only allopathic treatment (control group), while groups II and III received allopathic treatment with a daily supplementation of oral resveratrol (100 and $200 \mathrm{mg}$, resp.) for 12 months. In all groups, the changes of the studied parameters were monitored at 6 and 12 months from the initial evaluation. In groups II and III, resveratrol induced significant changes $(p<0.05)$ in the blood pressure, body mass index, as well as all parameters of the lipid profile, and glucose (in nondiabetic patients), compared to the control group. The supplementation of the allopathic treatment with resveratrol had a beneficial effect on all monitored parameters, which serve as major risk factors for stroke.
\end{abstract}

\section{Introduction}

Neurodegenerative, circulatory, and cardiovascular diseases and cancers are considered as direct consequence of the complex of phenomena, named "oxidative stress" [1-3]. Among these, stroke represents a leading cause of mortality worldwide and a major source of long-term disabilities and huge socioeconomic costs [4]. A recent study has revealed that about $90 \%$ of strokes can be attributed to the presence of 10 risk factors, including high blood pressure (BP), dyslipidemias, consumption of toxic substances (alcohol and tobacco), obesity, daily stress, sedentariness, and diabetes mellitus [5].

During the pathophysiology of stroke, reactive oxygen species (ROS) are generated, which can trigger chain reactions that destroy the neuronal membranes $[6,7]$. There are cumulative evidences suggesting that ROS can damage the cellular components [8], enhance the production of inflammatory mediators which in turn can lead to additional oxidative stress [9-12], and are involved in all the pathophysiological stages of neuronal death [13]. During ischemia, mitochondria (the main ROS-generating cellular components) suffer dysfunction, which causes an increase in oxidative stress. Increased production of ROS through mitochondria plays a role in the pathogenesis of stroke through direct damage to biomolecules resulting in necrosis, necroptosis and apoptosis, damaged endothelium-dependent vasodilator mechanisms, induction of mitochondrial permeability of transition, and interrupted excitation-contraction coupling [14].

Reactive oxygen species have an important role in normal physiological processes, being also implicated in a lot of disease processes, where they mediate damage to cell structures, including membranes, lipids, deoxyribonucleic acid (DNA), and proteins. Oxidative stress has an important role in the 
pathogenesis of ischemic brain injury that follows a cerebrovascular attack, having as goal the cerebral vasculature. The primary reactive oxygen species (like superoxide) and its derivatives, in animal models with ischemic stroke, cause vasodilatation by opening the potassium channels, altering the vascular reactivity, and breaking down the blood-brain barrier [15].

Diabetes mellitus and atherosclerosis are diseases that are associated with chronic inflammation produced by ROS [11, 16]. Consequently, stroke therapies should also consider secondary prophylaxis by addressing ROS on the medium and long term.

To neutralize these free radicals, the presence of potentially neutralizing agents (antioxidants) in the body is needed [17]. Particular attention is paid to the use of natural antioxidant agents that can be administered safely in humans in determined, verified, and standardized doses [18, 19]. Resveratrol (3,5,4'-trihydroxy-trans-diphenyl-ethylene) is well-known as a natural antioxidant, effective in combating oxidative stress and related inflammation [20, 21]. Due to its antioxidant effect, this substance can neutralize free radicals in the human body, thus reducing the resultant cellular aging process [22-24]. Resveratrol possesses phenolic functions $(\mathrm{Ar}-\mathrm{OH})$ susceptible to block-connect hydroperoxide radicals resulting from lipid peroxidation [25].

Numerous studies have shown the effectiveness of resveratrol in improving health and preventing chronic diseases. However, it is unclear whether these effects persist with prolonged administration of resveratrol $[20,26]$. This study investigates the effects of long-term resveratrol supplementation on BP, weight status, glucose, and lipid profile in patients who had a stroke in the last 12 months.

\section{Methods}

2.1. Study Design. This study included patients who had first stroke in the last 12 months, hospitalized for recovery treatment during 2011-2015 (patients were recruited each year during 5 years, each patient being under observation for a year). All patients were clinically stabilized after stroke. When they were included in this study, the patients were hospitalized in the Baile Felix Clinical Rehabilitation Hospital where they followed a complex medical physical rehabilitation program that imposed restrictions for BP values.

The research was conducted in accordance with the WMA Ethical Declaration of Helsinki and was approved by the Ethics Commission of the Council of Medicine and Pharmacy Faculty, University of Oradea, Romania. Each patient included in this study signed an informed consent form, before the inclusion.

Two hundred and twenty-eight patients were divided into three groups: group I (control), ( $n=92$ patients) who underwent allopathic (medical) treatment combined with medical physical rehabilitation, while groups II $(n=81$ patients) and III ( $n=55$ patients) received allopathic treatment and medical physical rehabilitation, combined with a 12-month supplementation with an oral daily dose of resveratrol (100 and $200 \mathrm{mg} /$ patient, resp.). The patients were distributed into groups using the method of selection for each group, depending on the patient's willingness of taking 100 or $200 \mathrm{mg}$ resveratrol, according to every patient's history and clinical characteristics, so that there were no significant differences between groups. Allopathic treatment was individualized for each patient, depending on the clinical characteristics and associated pathology. All patients were evaluated initially, at 6 months and at 12 months from the beginning of the treatment. The following parameters were monitored: $\mathrm{BP}$, weight status, lipid profile (total cholesterol, highdensity lipoprotein (HDL) cholesterol, low-density lipoprotein (LDL) cholesterol, and triglycerides), and glucose profile.

\subsection{Clinical Investigations}

2.2.1. Blood Pressure Measurement. Blood pressure measurement was performed following the 2007 Guidelines for the Management of Arterial Hypertension [27].

2.2.2. Body Mass Index (BMI) Determination. To determine the patients' weight status, the BMI was calculated using the following equation ( $\mathrm{BMI}=$ weight in kilograms divided by the square of height in meters, expressed in $\mathrm{kg} / \mathrm{m}^{2}$ ) [28].

2.3. Biochemical Analysis. Blood samples were obtained in the morning after a 12-14-hour meal break and were used to evaluate the levels of total cholesterol, triglycerides, HDL and LDL cholesterol, basal glucose, and glycosylated hemoglobin (HbA1c).

2.3.1. Lipid Profile. The cholesterol, triglycerides, HDL cholesterol, and LDL cholesterol assays were performed on the Beckman Coulter AU680 analyser using Beckman Coulter reagents, produced by Beckman Coulter Inc., Ireland. The methods of determination included the oxidase-peroxidase method for cholesterol, enzymatic glycerol-3-phosphate oxidase method for triglycerides, and colorimetric direct method for HDL and LDL cholesterol.

2.3.2. Fasting Blood Glucose. Basal glucose was determined by the hexokinase method, the values on an empty stomach being used for the selection of all subjects. A normal level of basal blood glucose was considered a plasmatic concentration of $<100 \mathrm{mg} / \mathrm{dL}$ [29].

2.3.3. Glycosylated Hemoglobin. Glycosylated hemoglobin was determined only for diabetic patients. It is a real image of glucose control over a period of 90-120 days retrospectively [26]. Determination was performed from venous blood collected on EDTA anticoagulant by HPLC (Gold Standard) using BioRad D-10 equipment and reagents.

2.3.4. Quality Control. The internal quality control was performed according to ISO 15189: 2013 standard. Variation coefficients were as follows: cholesterol CV\% $=2.05$, triglyceride CV\% $=1.95$, HDL cholesterol CV\% $=2.29$, LDL cholesterol $\mathrm{CV} \%=1.74$, glucose $\mathrm{CV} \%=2.05$, and $\mathrm{HbAlc}$ $\mathrm{CV} \%=0.82$.

2.4. Statistical Analysis. Statistical analysis was done using EPIINFO, version 6.0, a program of the Center for Disease Control and Prevention from Atlanta, adapted 
TABle 1: Demographic and clinical characteristics.

\begin{tabular}{|c|c|c|c|c|c|c|}
\hline \multirow[t]{2}{*}{ Characteristics } & \multicolumn{2}{|c|}{$\begin{array}{c}\text { Resveratrol } 100 \text { mg group } \\
\qquad(n=81)\end{array}$} & \multicolumn{2}{|c|}{$\begin{array}{c}\text { Resveratrol } 200 \mathrm{mg} \text { group } \\
(n=55)\end{array}$} & \multicolumn{2}{|c|}{$\begin{array}{l}\text { Control group } \\
\quad(n=92)\end{array}$} \\
\hline & Number & $\%$ & Number & $\%$ & Number & $\%$ \\
\hline \multicolumn{7}{|l|}{ Gender } \\
\hline Females & 32 & 39.51 & 21 & 38.18 & 37 & 40.22 \\
\hline Males & 49 & 60.49 & 34 & 61.82 & 55 & 59.78 \\
\hline \multicolumn{7}{|l|}{ Age } \\
\hline $55-60$ years & 4 & 4.94 & 2 & 3.63 & 5 & 5.43 \\
\hline $61-65$ years & 54 & 66.67 & 35 & 63.64 & 59 & 64.13 \\
\hline$>65$ years & 23 & 28.39 & 18 & 32.73 & 28 & 30.44 \\
\hline Average & \multicolumn{2}{|c|}{$65.03 \pm 8.24$} & \multicolumn{2}{|c|}{$64.52 \pm 8.05$} & \multicolumn{2}{|c|}{$64.78 \pm 6.32$} \\
\hline \multicolumn{7}{|l|}{ Risk factors } \\
\hline Obesity & 31 & 38.27 & 21 & 38.18 & 39 & 42.39 \\
\hline Toxicants (coffee, tobacco, and alcohol) & 37 & 45.68 & 23 & 41.82 & 42 & 45.65 \\
\hline Stress & 41 & 50.62 & 29 & 52.73 & 47 & 51.09 \\
\hline HBP & 64 & 79.01 & 43 & 78.18 & 72 & 78.26 \\
\hline Diabetes & 12 & 14.63 & 9 & 16.36 & 14 & 15.22 \\
\hline Dyslipidemia & 50 & 61.73 & 37 & 67.3 & 61 & 66.30 \\
\hline \multicolumn{7}{|l|}{ Diagnostic } \\
\hline Ischemic stroke & 59 & 72.64 & 41 & 74.54 & 68 & 73.91 \\
\hline Hemorrhagic stroke & 22 & 27.16 & 14 & 25.46 & 24 & 26.09 \\
\hline \multicolumn{7}{|l|}{ Time since stroke occurred } \\
\hline$<3$ months & 10 & 12.35 & 7 & 12.73 & 11 & 11.96 \\
\hline $3-6$ months & 46 & 56.79 & 30 & 54.54 & 50 & 54.35 \\
\hline 6-12 months & 25 & 30.86 & 18 & 32.73 & 31 & 33.70 \\
\hline Average (months) & \multicolumn{2}{|c|}{$5.08 \pm 1.22$} & \multicolumn{2}{|c|}{$5.13 \pm 1.14$} & \multicolumn{2}{|c|}{$5.17 \pm 1.16$} \\
\hline
\end{tabular}

to the medical statistics processing. Average parameter values, frequency ranges, standard deviations, and statistical significance tests by the Student method ( $t$ test) and $\chi^{2}$ were calculated.

The distribution of the tests is similar to normal, being used by assumptions involving numerical data. The $t$ test used was paired $t$ test. In order to obtain an indicator independent of the measurement units of the two variables, the Bravais-Pearson correlation coefficient was used. Statistical significance was assigned at a $p$ value of $<0.05$.

In order to interpret the magnitude of change in parameters at different time points, the "effect size" (ES) was measured. Based on statistical literature, the interpretation of this index was compiled, namely, small $\mathrm{ES}=0.20$, medium $\mathrm{ES}=0.50$, and large $\mathrm{ES}=0.80$. When expressing the findings of a quantitative study, ES is important because a $p$ value can identify if there is an effect but cannot reveal its magnitude [30, 31].

\section{Results}

3.1. Patients' Characteristics. In terms of demographic and clinical characteristics, there were no significant differences $(p>0.05)$ between the three groups (Table 1).

\subsection{Clinical Evaluations}

3.2.1. The Effect of Resveratrol on BP. Initially, there were no significant differences $(p>0.05)$ in the mean BP values between the three experimental groups (Table 2).

(1) Systolic BP. In the group receiving $100 \mathrm{mg}$ resveratrol, the systolic BP value decreased from $148.02 \mathrm{mmHg}$ to $143.12 \mathrm{mmHg}$ at 6 months $(p<0.05)$ and to $139.85 \mathrm{mmHg}$ in the next 6 months $(p<0.05)$. In the group receiving $200 \mathrm{mg}$ resveratrol, the systolic BP value decreased from $149.21 \mathrm{mmHg}$ to $142.02 \mathrm{mmHg}$ at 6 months $(p<0.05)$ and to $139.35 \mathrm{mmHg}$ in the next 6 months $(p<0.05)$. In the control group, systolic BP values decreased from $148.42 \mathrm{mmHg}$ to $146.10 \mathrm{mmHg}$ at 6 months $(p>0.05)$ and to $145.32 \mathrm{mmHg}$ in the next 6 months $(p>0.05)$.

Comparing data (Table 2) at the initial evaluation and at 12 months of treatment, the ES was 0.53 in the group receiving $100 \mathrm{mg}$ resveratrol, $\mathrm{ES}=0.53(p<0.05)$ and 0.65 in the group receiving $200 \mathrm{mg}$ resveratrol $(p<0.05)$, while in the control group, ES was $0.20(p>0.05)$.

(2) Diastolic BP. In the group receiving $100 \mathrm{mg}$ resveratrol, the diastolic BP value decreased from $88.29 \mathrm{mmHg}$ to $85.89 \mathrm{mmHg}$ at 6 months $(p>0.05)$ and to $84.27 \mathrm{mmHg}$ in 
TABLE 2: Effect of resveratrol on blood pressure.

\begin{tabular}{lcccc}
\hline \multirow{2}{*}{ Evaluation } & \multicolumn{4}{c}{ BP $(\mathrm{mmHg})$} \\
& Systolic BP & $\mathrm{ES}$ & Diastolic BP & ES \\
\hline Resveratrol 100 $m$ g group & & & \\
Initial & $148.02 \pm 15.28$ & - & $88.29 \pm 10.73$ & - \\
At 6 months & $143.12 \pm 15.16^{*}$ & 0.32 & $85.89 \pm 10.22$ & 0.22 \\
At 12 months & $139.85 \pm 14.82^{* c}$ & 0.22 & $84.27 \pm 10.18^{*}$ & 0.16 \\
Resveratrol 200 $m$ g group & & & \\
Initial & $149.21 \pm 15.13$ & - & $88.47 \pm 11.11$ & - \\
At 6 months & $142.02 \pm 15.27^{*}$ & 0.48 & $85.91 \pm 11.02$ & 0.23 \\
At 12 months & $139.35 \pm 14.81^{* c}$ & 0.17 & $84.10 \pm 10.78^{*}$ & 0.16 \\
Control group & & & & \\
Initial & $148.42 \pm 15.22$ & - & $87.61 \pm 11.25$ & - \\
At 6 months & $146.10 \pm 15.17$ & 0.16 & $86.39 \pm 11.32$ & 0.11 \\
At 12 months & $145.32 \pm 15.25$ & 0.05 & $85.67 \pm 11.11$ & 0.06 \\
\hline
\end{tabular}

Values are represented as mean $\pm \mathrm{SD}(n=81$ patients in the resveratrol $100 \mathrm{mg}$ group; $n=55$ patients in the resveratrol $200 \mathrm{mg}$ group; and $n=92$ patients in the control group); ${ }^{*} p<0.05$ versus initial value; ${ }^{\mathrm{c}}<0.05$ versus control group value.

the next 6 months $(p>0.05)$. In the group receiving $200 \mathrm{mg}$ resveratrol, the diastolic BP value decreased from $88.47 \mathrm{mmHg}$ to $85.91 \mathrm{mmHg}$ at 6 months $(p>0.05)$ and $84.10 \mathrm{mmHg}$ in the next 6 months $(p>0.05)$. In the control group, the diastolic BP value decreased from $87.61 \mathrm{mmHg}$ to $86.39 \mathrm{mmHg}$ at 6 months $(p>0.05)$ and $85.67 \mathrm{mmHg}$ in the next 6 months $(p>0.05)$, respectively (Table 2$)$.

Comparing data at the initial evaluation and at 12 months of treatment, ES was 0.37 in the group with $100 \mathrm{mg}$ resveratrol $(p<0.05), 0.39$ in the group receiving $200 \mathrm{mg}$ resveratrol $(p<0.05)$, and 0.17 for the control group without resveratrol supplementation $(p>0.05)$.

3.2.2. The Effect of Resveratrol on the Weight Status and BMI. Initially, there were no significant differences $(p>0.05)$ in BMI values between the two experimental groups. After a 12 -month administration of resveratrol at 100 and $200 \mathrm{mg}$, we recorded a significant decrease $(p<0.05)$ in the mean BMI values, compared to the control group (Table 3 ).

The mean BMI values decreased after 6 months in the group receiving $100 \mathrm{mg}$ resveratrol from $29.47 \mathrm{~kg} / \mathrm{m}^{2}$ to $27.97 \mathrm{~kg} / \mathrm{m}^{2}(p>0.05)$, resulting in an $\mathrm{ES}=0.35$; in the group receiving $200 \mathrm{mg}$ resveratrol, from $29.50 \mathrm{~kg} / \mathrm{m}^{2}$ to $27.56 \mathrm{~kg} / \mathrm{m}^{2}(p>0.05)$, resulting in an $\mathrm{ES}=0.45$; in the nonresveratrol group, the BMI had a minimal decrease from $29.95 \mathrm{~kg} / \mathrm{m}^{2}$ to $29.42 \mathrm{~kg} / \mathrm{m}^{2}(p>0.05)$, resulting in an $\mathrm{ES}=0.12$.

In the next 6 months, in the group receiving $100 \mathrm{mg}$ resveratrol, a decrease in BMI was noticed from $27.97 \mathrm{~kg} / \mathrm{m}^{2}$ to $26.75 \mathrm{~kg} / \mathrm{m}^{2}(p>0.05)$, resulting in an $\mathrm{ES}=0.27$; in the group receiving $200 \mathrm{mg}$ resveratrol, a decrease in BMI was noticed from $27.56 \mathrm{~kg} / \mathrm{m}^{2}$ to $25.77 \mathrm{~kg} / \mathrm{m}^{2}(p<0.05)$, resulting in an $\mathrm{ES}=0.42$; in the group without resveratrol, a decrease in BMI was noticed from $29.42 \mathrm{~kg} / \mathrm{m}^{2}$ to $29.31 \mathrm{~kg} / \mathrm{m}^{2}(p>0.05)$, resulting in an $\mathrm{ES}=0.02$.
Comparing data at the initial evaluation and at 12 months of treatment, ES was 0.64 (from $29.47 \mathrm{~kg} / \mathrm{m}^{2}$ to $\left.26.75 \mathrm{~kg} / \mathrm{m}^{2}, p<0.05\right)$ in the group receiving $100 \mathrm{mg}$ resveratrol, 0.87 (from $29.50 \mathrm{~kg} / \mathrm{m}^{2}$ to $25.77 \mathrm{~kg} / \mathrm{m}^{2}, p<0.05$ ) in the group receiving $200 \mathrm{mg}$ resveratrol, and 0.14 (from $29.95 \mathrm{~kg} / \mathrm{m}^{2}$ to $29.31 \mathrm{~kg} / \mathrm{m}^{2}, p>0.05$ ) in the group without resveratrol supplementation (Table 3 ).

\subsection{Biochemical Analysis}

3.3.1. The Effect of Resveratrol on the Lipid Profile. In all groups, the lipid profile improved significantly both at 6 months and at 12 months $(p<0.05)$. In the resveratrol groups, the lipid profile improved significantly over the 12 months $(p<0.05)$, compared with the control group (Table 4). After 12 months, resveratrol administration irrespective of the dose had a substantial effect on all lipid profile parameters, especially on triglycerides $(\mathrm{ES}=1.81$ at $100 \mathrm{mg}$ and $\mathrm{ES}=1.95$ at $200 \mathrm{mg}$ ) and serum cholesterol $(\mathrm{ES}=1.51$ at $100 \mathrm{mg}$ and $\mathrm{ES}=1.63$ at $200 \mathrm{mg}$ ). For the control group, the ES was greater than 1 as well, in the case of triglycerides and serum cholesterol ( $\mathrm{ES}=1.39$ and $\mathrm{ES}=1.07$, resp.). Compared to the control group, the effect of resveratrol $100 \mathrm{mg}$ was 2.02 times greater for HDL cholesterol ( $E S=1.25$ versus $\mathrm{ES}=0.62)$ and of 2.34 for $\mathrm{LDL}$ cholesterol $(\mathrm{ES}=1.24$ versus $\mathrm{ES}=0.53)$. Also, compared to the control group, the effect of resveratrol $200 \mathrm{mg}$ was 2.11 times greater for HDLcholesterol $(\mathrm{ES}=1.31$ versus $\mathrm{ES}=0.62)$ and of 2.42 times for LDL-cholesterol $(\mathrm{ES}=1.28$ versus $\mathrm{ES}=0.53)$.

\subsubsection{The Effect of Resveratrol on the Glycemic Profile}

(1) Basal Glycemia. In diabetic patients, blood glucose levels decreased insignificantly $(p>0.05)$ after 6 months, in the group receiving $100 \mathrm{mg}$ resveratrol (from $142.18 \mathrm{mg} / \mathrm{dL}$ to $136.29 \mathrm{mg} / \mathrm{dL}, \mathrm{ES}=0.39$ ) and in the group receiving $200 \mathrm{mg}$ (from $142.46 \mathrm{mg} / \mathrm{dL}$ to $136.21 \mathrm{mg} / \mathrm{dL}, \mathrm{ES}=0.41$ ). The decrease was significant compared to the control group where the blood glucose values had a minimal decrease (from $142.47 \mathrm{mg} / \mathrm{dL}$ to $141.81 \mathrm{mg} / \mathrm{dL}, \mathrm{ES}=0.04$ ).

In the following 6 months, blood glucose decreased in the group receiving $100 \mathrm{mg}$ resveratrol from 136.29 to $134.24 \mathrm{mg} / \mathrm{dL}, \mathrm{ES}=0.17$, and in the group receiving $200 \mathrm{mg}$ from 136.21 to $133.89 \mathrm{mg} / \mathrm{dL}, \mathrm{ES}=0.16$. In the group without resveratrol, the effect was $\mathrm{ES}=0.08$ (from 141.81 to $140.58 \mathrm{mg} / \mathrm{dL}$ ).

Comparing the results of the initial evaluation and 12 months of assessment in diabetic patients, ES was 0.52 (from $142.18 \mathrm{mg} / \mathrm{dL}$ to $134.24 \mathrm{mg} / \mathrm{dL}, p>0.05$ ) in the group receiving $100 \mathrm{mg}$ resveratrol, 0.56 in the group receiving $200 \mathrm{mg}$ resveratrol (from $142.46 \mathrm{mg} / \mathrm{dL}$ to $133.89 \mathrm{mg} / \mathrm{dL}, p>0.05$ ) and 0.12 (from $142.47 \mathrm{mg} / \mathrm{dL}$ to $140.58 \mathrm{mg} / \mathrm{dL}, p>0.05$ ) in the group without resveratrol supplementation.

In nondiabetic patients, blood glucose levels decreased significantly $(p<0.05)$ after 6 months in the group receiving $100 \mathrm{mg}$ of resveratrol (from $96.67 \mathrm{mg} / \mathrm{dL}$ to $91.23 \mathrm{mg} / \mathrm{dL}$, $\mathrm{ES}=0.48$ ) and in the group receiving $200 \mathrm{mg}$ (from $96.98 \mathrm{mg} / \mathrm{dL}$ to $91.21 \mathrm{mg} / \mathrm{dL}, \mathrm{ES}=0.51$ ). The decrease was significant from the baseline and from the control group 
TABLE 3: Effect of resveratrol on the weight status and on the body mass index.

\begin{tabular}{|c|c|c|c|c|c|c|}
\hline \multirow{2}{*}{ Weight status } & \multicolumn{2}{|c|}{ Resveratrol 100 mg group } & \multicolumn{2}{|c|}{ Resveratrol $200 \mathrm{mg}$ group } & \multicolumn{2}{|c|}{ Control group } \\
\hline & Number of patients & $\%$ & Number of patients & $\%$ & Number of patients & $\%$ \\
\hline Normal weight & 17 & 20.99 & 11 & 20.00 & 17 & 18.48 \\
\hline Overweight & 33 & 40.74 & 23 & 41.82 & 36 & 39.13 \\
\hline Class I obesity & 18 & 22.22 & 12 & 21.82 & 22 & 23.91 \\
\hline Class II obesity & 9 & 11.11 & 7 & 12.73 & 12 & 13.04 \\
\hline Class III obesity & 4 & 4.94 & 2 & 3.64 & 5 & 5.43 \\
\hline BMI average (initial) & \multicolumn{2}{|c|}{$29.47 \pm 4.26$} & \multicolumn{2}{|c|}{$29.50 \pm 4.27$} & \multicolumn{2}{|c|}{$29.95 \pm 4.49$} \\
\hline Normal weight & 21 & 25.93 & 15 & 27.27 & 17 & 18.48 \\
\hline Overweight & 33 & 40.74 & 24 & 43.64 & 36 & 39.13 \\
\hline Class I obesity & 16 & 19.75 & 9 & 16.36 & 23 & 25.00 \\
\hline Class II obesity & 8 & 9.88 & 5 & 9.09 & 11 & 11.96 \\
\hline Class II obesity & 3 & 3.70 & 2 & 3.64 & 5 & 5.43 \\
\hline BMI average (at six months) & \multicolumn{2}{|c|}{$27.97 \pm 4.44^{c}$} & \multicolumn{2}{|c|}{$27.56 \pm 4.28^{c}$} & \multicolumn{2}{|l|}{$29.42 \pm 4.72$} \\
\hline ES & \multicolumn{2}{|l|}{0.35} & \multicolumn{2}{|l|}{0.45} & \multicolumn{2}{|l|}{0.12} \\
\hline Normal weight & 28 & 34.57 & 19 & 34.55 & 18 & 19.57 \\
\hline Overweight & 36 & 44.44 & 25 & 45.45 & 36 & 39.13 \\
\hline Class I obesity & 10 & 12.35 & 6 & 10.91 & 22 & 23.91 \\
\hline Class II obesity & 5 & 6.17 & 4 & 7.27 & 11 & 11.96 \\
\hline Class III obesity & 2 & 2.47 & 1 & 1.82 & 5 & 5.43 \\
\hline BMI average (at 12 months) & \multicolumn{2}{|c|}{$26.75 \pm 4.12^{* c}$} & \multicolumn{2}{|c|}{$25.77 \pm 4.13^{* c}$} & \multicolumn{2}{|l|}{$29.31 \pm 4.55$} \\
\hline ES & \multicolumn{2}{|l|}{0.27} & \multicolumn{2}{|l|}{0.42} & \multicolumn{2}{|l|}{0.02} \\
\hline
\end{tabular}

Values are represented as mean $\pm \mathrm{SD}(n=81$ patients in the resveratrol $100 \mathrm{mg}$ group; $n=55$ patients in the resveratrol $200 \mathrm{mg}$ group; and $n=92$ patients in the control group); ${ }^{*} p<0.05$ versus initial value; ${ }^{\mathrm{c}}<0.05$ versus control group value.

TABLE 4: Effect of resveratrol on the lipid profile.

\begin{tabular}{|c|c|c|c|c|c|c|}
\hline \multirow{2}{*}{ Lipid profile } & \multicolumn{2}{|c|}{ Resveratrol $100 \mathrm{mg}$ group } & \multicolumn{2}{|c|}{ Resveratrol $200 \mathrm{mg}$ group } & \multicolumn{2}{|c|}{ Control group } \\
\hline & $\mathrm{M} \pm \mathrm{SD}$ & ES & $\mathrm{M} \pm \mathrm{SD}$ & ES & $\mathrm{M} \pm \mathrm{SD}$ & ES \\
\hline \multicolumn{7}{|c|}{ Serum cholesterol $(\mathrm{mg} / \mathrm{dL})$} \\
\hline Initial & $257.56 \pm 23.89$ & - & $256.61 \pm 22.23$ & - & $255.14 \pm 22.08$ & - \\
\hline At 6 months & $236.75 \pm 22.82^{* c}$ & 0.87 & $236.16 \pm 22.61^{* c}$ & 0.92 & $247.25 \pm 21.67^{*}$ & 0.36 \\
\hline At 12 months & $221.52 \pm 21.75^{* c}$ & 0.67 & $220.44 \pm 21.56^{* c}$ & 0.70 & $231.41 \pm 20.78^{*}$ & 0.73 \\
\hline \multicolumn{7}{|c|}{ HDL cholesterol $(m g / d L)$} \\
\hline Initial & $39.27 \pm 5.27$ & - & $39.36 \pm 5.16$ & - & $38.76 \pm 5.29$ & - \\
\hline At 6 months & $43.78 \pm 5.28^{* \mathrm{c}}$ & 0.86 & $43.92 \pm 5.18^{* c}$ & 0.88 & $40.17 \pm 5.21$ & 0.27 \\
\hline At 12 months & $45.87 \pm 5.31^{* c}$ & 0.40 & $46.12 \pm 5.11^{* c}$ & 0.42 & $42.02 \pm 5.14^{*}$ & 0.36 \\
\hline \multicolumn{7}{|c|}{ LDL cholesterol $(m g / d L)$} \\
\hline Initial & $143.34 \pm 15.41$ & & $142.82 \pm 15.26$ & & $143.48 \pm 15.46$ & \\
\hline At 6 months & $127.66 \pm 13.88^{* c}$ & 1.02 & $125.01 \pm 13.11^{* c}$ & 1.04 & $137.92 \pm 13.83^{*}$ & 0.36 \\
\hline At 12 months & $124.21 \pm 13.67^{* c}$ & 0.25 & $123.22 \pm 13.13^{* c}$ & 0.29 & $135.21 \pm 13.60^{*}$ & 0.20 \\
\hline \multicolumn{7}{|c|}{ Triglycerides $(m g / d L)$} \\
\hline Initial & $195.36 \pm 20.16$ & - & $195.69 \pm 20.24$ & - & $194.45 \pm 20.24$ & - \\
\hline At 6 months & $172.73 \pm 18.49^{*}$ & 1.12 & $170.75 \pm 18.23^{* c}$ & 1.23 & $177.54 \pm 19.01^{*}$ & 0.84 \\
\hline At 12 months & $158.78 \pm 16.85^{* \mathrm{cr}}$ & 0.75 & $156.28 \pm 16.28^{* c}$ & 0.79 & $166.28 \pm 17.77^{*}$ & 0.59 \\
\hline
\end{tabular}

Values are represented as mean $\pm \mathrm{SD}(n=81$ patients in the resveratrol $100 \mathrm{mg}$ group; $n=55$ patients in the resveratrol $200 \mathrm{mg}$ group; and $n=92$ patients in the control group); ${ }^{*} p<0.05$ versus initial value; ${ }^{\mathrm{c}}<0.05$ versus control group value; ${ }^{\mathrm{r}}<0.05$ versus resveratrol $200 \mathrm{mg}$ group value. 
where the blood glucose values had a minimal decrease (from $95.71 \mathrm{mg} / \mathrm{dL}$ to $94.55 \mathrm{mg} / \mathrm{dL}, \mathrm{ES}=0.1$ ).

In the following 6 months, blood glucose decreased in the group receiving $100 \mathrm{mg}$ resveratrol from 91.23 to $87.12 \mathrm{mg} / \mathrm{dL}, \mathrm{ES}=0.38$, in the group receiving $200 \mathrm{mg}$ from 91.21 to $86.11 \mathrm{mg} / \mathrm{dL}, \mathrm{ES}=0.48$, and in the group without resveratrol, $\mathrm{ES}=0.11$ (from 94.55 to $93.33 \mathrm{mg} / \mathrm{dL}$ ). In both groups with resveratrol, the decrease was significant compared to the value at six months and compared to the control group (Table 5).

Comparing the results of the initial evaluation and 12 months of assessment in nondiabetic patients, ES was 0.85 (from $96.67 \mathrm{mg} / \mathrm{dL}$ to $87.12 \mathrm{mg} / \mathrm{dL}, p<0.05$ ) in the group receiving $100 \mathrm{mg}$ resveratrol, 0.97 (from $96.98 \mathrm{mg} / \mathrm{dL}$ to $86.11 \mathrm{mg} / \mathrm{dL}, p<0.05)$ in the group receiving $200 \mathrm{mg}$ resveratrol, and 0.20 (from $95.71 \mathrm{mg} / \mathrm{dL}$ to $93.33 \mathrm{mg} / \mathrm{dL}, p>0.05$ ) in the group without resveratrol supplementation.

(2) Glycosylated Hemoglobin. Glycated hemoglobin values decreased after 6 months as follows: in the group receiving $100 \mathrm{mg}$ resveratrol from $7.13 \%$ to $6.72 \%(p>0.05$, $\mathrm{ES}=0.27$ ); in the group receiving $200 \mathrm{mg}$ resveratrol from $7.15 \%$ to $6.66 \%(p>0.05, \mathrm{ES}=0.33)$; and in the group without resveratrol supplementation, there was a minimal decrease in HbA1c values (from $7.10 \%$ to $7.09 \%, p>0.05$, $\mathrm{ES}=0.01)$.

In the next 6 months, a decrease in HbAlc mean values was noticed from $6.72 \%$ to $6.61 \% \quad(p>0.05$, $\mathrm{ES}=0.08)$ and from $6.66 \%$ to $6.55 \%(p>0.05, \mathrm{ES}=0.08)$ in the group receiving $200 \mathrm{mg}$ resveratrol. In the group without resveratrol supplementation, ES was 0.03 (from $7.09 \%$ to $7.05 \%, p>0.05$ ) (Table 6).

Comparing data at the initial evaluation and at 12 months of treatment, ES was 0.34 (from $7.13 \%$ to $6.61 \%$, $p>0.05)$ in the group receiving $100 \mathrm{mg}$ resveratrol, 0.40 (from $7.15 \%$ to $6.55 \%, p>0.05$ ) in the group receiving $200 \mathrm{mg}$ resveratrol, and 0.03 (from $7.10 \%$ to $7.05 \%, p>$ $0.05)$ in the group without resveratrol supplementation.

\section{Discussion}

One of the most prevalent cardiovascular illness is stroke. This is a main problem not only in matter of health, both in terms of sequelae and the destructive impact on the quality of life of the patient, implicitly on his or her relatives, but also in the point of view of increasing mortality.

Comprehensive research over the last few decades has discovered multiple mechanisms by which resveratrol changes cardiovascular risk factors [32, 33]. Diabetes, hypercholesterolemia, and hypertension, by decreasing bioactive nitric oxide, lead to high production of reactive oxygen species in vessel walls. Endothelial dysfunction is a significant mechanism of cerebrovascular injury, deriving in part from the excessive generation of reactive oxygen species [32].

Here, we show that long-term resveratrol supplementation in patients poststroke had a beneficial effect on these parameters that serve as major risk factors for stroke.

To evaluate the long-term dose-dependent resveratrol potential in the secondary prevention of stroke, in this study,
TABLE 5: Effect of resveratrol on glucose.

\begin{tabular}{lcccc}
\hline \multirow{2}{*}{ Evaluation } & \multicolumn{4}{c}{ Glucose $(\mathrm{mg} / \mathrm{dL})$} \\
& Diabetics & ES & Nondiabetics & ES \\
\hline Resveratrol 100 $m$ g group & & & \\
Initial & $142.18 \pm 15.22$ & - & $96.67 \pm 11.26$ & - \\
At 6 months & $136.29 \pm 14.48^{\mathrm{c}}$ & 0.39 & $91.23 \pm 10.75^{* \mathrm{c}}$ & 0.48 \\
At 12 months & $134.24 \pm 14.31$ & 0.14 & $87.12 \pm 10.61^{* \mathrm{c}}$ & 0.38 \\
Resveratrol 200 $m g$ group & & & \\
Initial & $142.46 \pm 15.24$ & - & $96.98 \pm 11.23$ & - \\
At 6 months & $136.21 \pm 14.56^{\mathrm{c}}$ & 0.41 & $91.21 \pm 10.67^{* \mathrm{c}}$ & 0.51 \\
At 12 months & $133.89 \pm 15.68$ & 0.16 & $86.11 \pm 10.78^{* \mathrm{c}}$ & 0.48 \\
Control group & & & & \\
Initial & $142.47 \pm 15.83$ & - & $95.71 \pm 11.63$ & - \\
At 6 months & $141.81 \pm 15.31$ & 0.04 & $94.55 \pm 11.22$ & 0.10 \\
At 12 months & $140.58 \pm 15.62$ & 0.08 & $93.33 \pm 11.28$ & 0.11 \\
\hline
\end{tabular}

Values are represented as mean $\pm \mathrm{SD}(n=13$ diabetic and $n=68$ nondiabetic patients in the resveratrol $100 \mathrm{mg}$ group; $n=11$ diabetic and $n=44$ nondiabetic patients in the resveratrol $200 \mathrm{mg}$ group; and $n=16$ diabetic and $n=76$ nondiabetic patients in the control group); ${ }^{*} p<0.05$ versus initial value; ${ }^{\mathrm{c}}<0.05$ versus control group value.

we compared the effects of two different doses of resveratrol in terms of effectiveness on BP, weight status, lipid profile, and glucose profile, in patients who have suffered a stroke in the past 12 months.

We chose doses of $100 \mathrm{mg}$ and $200 \mathrm{mg}$ resveratrol/day, respectively, due to the fact that it has been shown that doses of resveratrol lower than $0.5 \mathrm{~g}$ per person may be sufficient to decrease blood glucose levels, improve insulin action, and generate cardioprotective effect and other favorable effects $[34,35]$. Moreover, some studies imply that in certain cases, resveratrol can be more efficient in lower doses compared to the effect produced by this compound in higher doses $[36,37]$. Nevertheless, studies upon the toxicity of resveratrol in humans reveal that doses up to $0.5 \mathrm{~g}$ per day for long periods may determine only reversible and moderate side effects, being well tolerated [38].

We recorded significant decreases in BP, BMI, lipid profile parameters, and glucose in patients, treated with a daily oral dose of 100 or $200 \mathrm{mg}$ resveratrol for a year, as compared to the control group. The effect of resveratrol in $200 \mathrm{mg}$ dose was significantly better than in $100 \mathrm{mg}$ dose, on triglyceride values alone. Patients were monitored for a period of 12 months, during which no new vascular attack occurred in any group; however, in the resveratrol groups, the monitored parameters were significantly improved. Previous studies have revealed that stroke risk factor identification and treatment can considerably prevent long-term morbidity and mortality and can diminish ischemic stroke after a first stroke [38, 39].

Besides age, the most significant cardiovascular risk factor for developing both hemorrhagic and ischemic stroke is hypertension. In addition, hypertension predisposes to risk of cardiac diseases and atherosclerosis, thereby determining cerebral embolism. The inflammatory mechanisms hold an 
TABLE 6: Effect of resveratrol on HbAlc.

\begin{tabular}{lccccc}
\hline \multirow{2}{*}{ Evaluation } & \multicolumn{4}{c}{ HbA1c (\%) } \\
& \multicolumn{2}{c}{ Resveratrol $100 \mathrm{mg}$ group } & \multicolumn{2}{c}{ Resveratrol 200 mg group } & \multicolumn{2}{c}{ Control group } \\
& $\mathrm{M} \pm \mathrm{SD}$ & $\mathrm{ES}$ & $\mathrm{M} \pm \mathrm{SD}$ & $\mathrm{ES}$ & - \\
\hline Initial & $7.13 \pm 1.51$ & - & $7.15 \pm 1.50$ & - & $7.10 \pm 1.47$ \\
At 6 months & $6.72 \pm 1.40$ & 0.27 & $6.66 \pm 1.41$ & 0.33 & $7.09 \pm 1.43$ \\
At 12 months & $6.61 \pm 1.38$ & 0.08 & $6.55 \pm 1.40$ & 0.08 & $7.05 \pm 1.46$ \\
\hline
\end{tabular}

Values are represented as mean $\pm \mathrm{SD}(n=13$ diabetic patients in the resveratrol $100 \mathrm{mg}$ group; $n=11$ diabetic patients in the resveratrol $200 \mathrm{mg}$ group; and $n=16$ diabetic patients in the control group).

important role in the progression and pathogenesis of atherosclerosis, thrombosis, plaque rupture, and stroke [40]. As we have previously mentioned, endothelial dysfunction is regarded as an important mechanism for cerebrovascular damages [32].

Several studies have reported an increased level of lipid peroxidation and oxidative stress biomarkers in patients with essential or secondary hypertension [41-44]. Other studies showed that the production of $\mathrm{H}_{2} \mathrm{O}_{2}$ and 13hydroxyoctadecadienoic acid, a ROS production marker, is significantly higher in these patients than in subjects with normal BP $[45,46]$. Therefore, due to its antioxidant activity, resveratrol may have beneficial effects in reducing high BP. In a study performed on 97 patients, Theodotou et al. concluded that adding resveratrol to the standard antihypertensive treatment effectively reduces BP [47]. This may occur through increasing the production of nitric oxide in blood vessels, where it activates the guanylate cyclase enzyme, which facilitates vasodilatation $[40,48]$.

Our study demonstrated that the association of resveratrol to allopathic treatment for 12 months resulted in a significant decrease in BP $(p<0.05)$ in poststroke patients.

The evaluations at 6 months and 12 months did not indicate significant differences between the two batches with different doses of resveratrol on the effect on BP.

Multiple studies have demonstrated that resveratrol is able to determine cell cycle arrest and counteracts adipogenesis, in the same time having a proapoptotic effect in adipocytes of mice and humans [49].

Resveratrol is a substance with multiple desirable antiobesity effects on adipocytes in body storage tissues. It also diminishes adipogenesis and viability in preadipocyte maturation, which is mediated by the regulation of specific adipocyte and enzyme-specific transcription factors as well as genes that modulate mitochondrial function. Resveratrol also increases the processes of lipolysis and reduces lipogenesis in mature adipocytes [50].

In this study, following a 12-month administration of resveratrol $100 \mathrm{mg}$ and $200 \mathrm{mg}$, respectively, there was a significant decrease in mean BMI when compared to the control group, with no significant differences between the groups with 100 and $200 \mathrm{mg}$. BMI values have changed over the 12 months even though most patients kept their weight, the results showing a decrease of this index.

Dyslipidemia and steatohepatitis determined by the atherogenic diet in mice were improved by resveratrol, its beneficial effects being correlated with the altered expression of hepatic genes implicated in lipid metabolism [51]. In obese mice, given a high-calorie diet, resveratrol significantly decreased the body weight [52-54]. Studies on the nonhuman primate (Microcebus murinus) found that the administration of $200 \mathrm{mg} / \mathrm{kg} /$ day of resveratrol caused an increase in basal metabolism and energy consumption, suggesting a potential mechanism for weight loss $[55,56]$. In this paper, favorable changes in the lipid profile in all three groups, both at 6 months and at 12 months, may be associated with the hygienic-dietary regimen imposed on poststroke patients.

Six months after starting resveratrol administration, a significant decrease in cholesterol and lipid profile change in favor of the patient was observed. Significant values in lipid profile changes were even more noticeable 12 months after resveratrol administration started. In order to define the lipid profile, a great importance had the increase in HDL cholesterol values and decrease in LDL cholesterol, respectively, after the administration of resveratrol. Triglyceride levels decreased significantly in the groups of patients with resveratrol. Between the two resveratrol groups, there were significant differences in triglyceride values, which meaningfully decreased in the group with $200 \mathrm{mg} /$ day/patient.

In the literature, it has been highlighted that resveratrol has antidiabetic effects, with a positive effect on both insulin and pancreatic $\beta$ cells, and impedes complications of the disease $[57,58]$. Resveratrol activates the Sirtuin 1 (SIRT1) pathways, according to some recent studies on how resveratrol works in diabetes. SIRT1 expression and activity were significantly reduced in experimental models of diabetes mellitus. Some of the favorable effects of resveratrol on adjusting glucose homeostasis are mediated by the activation of adenosine monophosphate-activated kinase (AMPK). Modification of AMPK activity, under hyperglycemic conditions, correlates with insulin resistance and tissue damage and with hyperglycemia, supporting a key role of AMPK in type 2 diabetes [59].

Data existing in the literature show diverse effective doses of resveratrol in insulin-resistant individuals. Thus, it is important to understand that the mechanisms of action of resveratrol can vary according to its dose. Treatment with lower doses of resveratrol activates SIRT1, while higher doses activate AMPK in a way independent of SIRT1 [60].

We noticed a decrease in blood glucose levels, both in the first and last six months of administration. The changes were not significant in diabetic patients for none of the studied groups; however, the effect was more favorable in the resveratrol groups. Oxidative stress plays an important role in the development of insulin resistance and can be neutralized by 


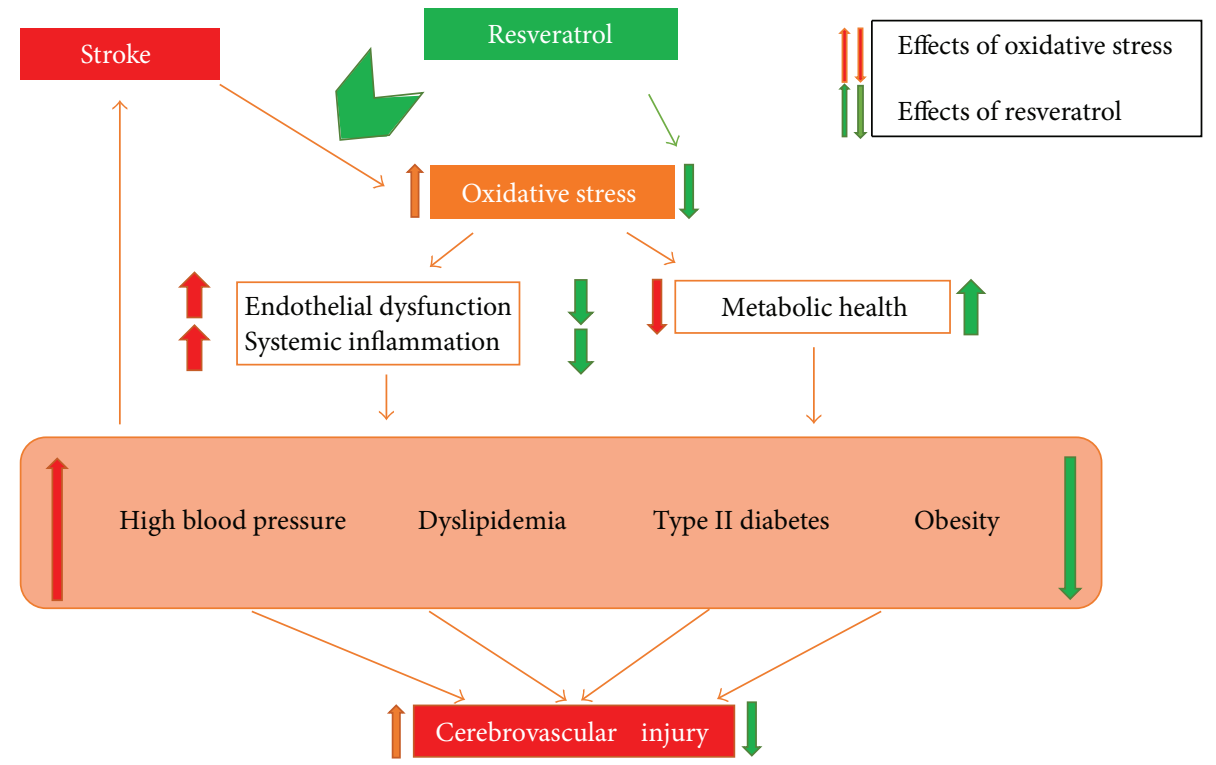

Figure 1

the antioxidant effect of resveratrol [59, 61]. Previous studies indicated increased insulin sensitivity in patients treated with resveratrol [62] and explained these effects by the decrease in oxidative stress, as evidenced by the monitoring of some biochemical parameters.

Recommendations: six months after starting resveratrol administration, a significant decrease in cholesterol and LDL cholesterol was observed. Thus, adding resveratrol to standard lipid-lowering medication may help restoring normal lipid profile values in these patients (Figure 1). Observation of the lifestyle and nutrition subsequent to a stroke of a patient was not an objective in itself of our study but could be a direction for further research.

\section{Conclusions}

The supplementation of allopathic treatment with resveratrol had a beneficial effect on all monitored parameters that serve as major risk factors for stroke. The response to treatment was better in the $200 \mathrm{mg}$ resveratrol group, but the differences were not significant compared to the $100 \mathrm{mg}$ resveratrol group. Therefore, resveratrol can be used as a complementary, long-term therapy, as well as a beneficial adjuvant in the secondary prevention of stroke.

\section{Abbreviations}

BMI: $\quad$ Body mass index

BP: $\quad$ Blood pressure

DNA: Deoxyribonucleic acid

ES: $\quad$ Effect size

HbA1c: Glycosylated hemoglobin

HDL: High-density lipoprotein

LDL: Low-density lipoprotein

ROS: Reactive oxygen species

SIRT1: Sirtuin 1

AMPK: Adenosine monophosphate-activated kinase.

\section{Conflicts of Interest}

The authors declare that they have no conflicts of interest.

\section{References}

[1] H. D. Loukianoff and S. L. McLaughlin, Oxidative Stress Indices: Analytical Aspects and Significance in Handbook of Oxidants and Antioxidants in Exercise, C. K. L. Sen and O. Pacher, Eds., Elsevier, Amsterdam, 2000.

[2] W. Dröge, "Free radicals in the physiological control of cell function," Physiological Reviews, vol. 82, no. 1, pp. 47-95, 2002.

[3] D. P. Jones, "Redefining oxidative stress," Antioxidants \& Redox Signaling, vol. 8, no. 9-10, pp. 1865-1879, 2006.

[4] H. Jaffer, V. B. Morris, D. Stewart, and V. Labhasetwar, "Advances in stroke therapy," Drug Delivery and Translational Research, vol. 1, no. 6, pp. 409-419, 2011.

[5] M. J. O'Donnell, D. Xavier, L. Liu et al., "Risk factors for ischaemic and intracerebral haemorrhagic stroke in 22 countries (the Interstroke study): a case-control study," Lancet, vol. 376, no. 9735, pp. 112-123, 2010.

[6] M. Valko, D. Leibfritz, J. Moncol, M. T. D. Cronin, M. Mazur, and J. Telser, "Free radicals and antioxidants in normal physiological functions and human disease," The International Journal of Biochemistry \& Cell Biology, vol. 39, no. 1, pp. 4484, 2007.

[7] D. Harrison, K. K. Griendling, U. Landmesser, B. Hornig, and H. Drexler, "Role of oxidative stress in atherosclerosis," American Journal of Cardiology, vol. 91, no. 3, pp. 7-11, 2003.

[8] V. Janardhan and A. I. Qureshi, "Mechanisms of ischemic brain injury," Current Cardiology Reports, vol. 6, no. 2, pp. 117-123, 2004.

[9] J. J. Haddad, "Redox regulation of pro-inflammatory cytokines and IkappaB- $\alpha / \mathrm{NF}-\kappa \mathrm{B}$ nuclear translocation and activation," Biochemical and Biophysical Research Communications, vol. 296, no. 4, pp. 847-856, 2002. 
[10] R. A. Roberts, D. L. Laskin, C. V. Smith et al., "Nitrative and oxidative stress in toxicology and disease," Toxicological Sciences, vol. 112, no. 1, pp. 4-16, 2009.

[11] T. Finkel and N. J. Holbrook, "Oxidants, oxidative stress and the biology of ageing," Nature, vol. 408, no. 6809, pp. 239$247,2000$.

[12] D. Copolovici, S. Bungau, R. Boscencu, D. M. Tit, and L. Copolovici, "The fatty acids composition and antioxidant activity of walnut cold press oil," Revista de Chimie Bucharest, vol. 68, no. 3, pp. 507-509, 2017.

[13] W. Cao, J. M. Carney, A. Duchon, R. A. Floyd, and M. Chevion, "Oxygen free radical involvement in ischemia and reperfusion injury to brain," Neuroscience Letters, vol. 88, no. 2, pp. 233-238, 1988.

[14] T. Kalogeris, Y. Bao, and R. J. Korthuis, "Mitochondrial reactive oxygen species: a double edged sword in ischemia/ reperfusion vs preconditioning," Redox Biology, vol. 2, pp. 702-714, 2014

[15] C. L. Allen and U. Bayraktutan, "Oxidative stress and its role in the pathogenesis of ischaemic stroke," International Journal of Stroke, vol. 4, no. 6, pp. 461-470, 2009.

[16] H. Kaneto, N. Katakami, M. Matsuhisa, and T. A. Matsuoka, "Role of reactive oxygen species in the progression of type 2 diabetes and atherosclerosis," Mediators of Inflammation, vol. 2010, Article ID 453892, 11 pages, 2010.

[17] M. L. Urso and P. M. Clarkson, "Oxidative stress, exercise, and antioxidant supplementation," Toxicology, vol. 189, no. 1-2, pp. 41-54, 2003.

[18] V. Brown, K. Patel, M. Viskaduraki et al., "Repeat dose study of the cancer chemopreventive agent resveratrol in healthy volunteers: safety, pharmacokinetics and effect on the insulinlike growth factor axis," Cancer Research, vol. 70, no. 22, pp. 9003-9011, 2010.

[19] A. Cherubini, C. Ruggiero, C. Morand et al., "Dietary antioxidants as potential pharmacological agents for ischemic stroke," Current Medicinal Chemistry, vol. 15, no. 12, pp. 1236-1248, 2008.

[20] J. M. Smoliga, J. A. Baur, and H. A. Hausenblas, "Resveratrol and health-a comprehensive review of human clinical trials," Molecular Nutrition \& Food Research, vol. 55, no. 8, pp. 11291141, 2011.

[21] D. Bagchi, D. K. Das, A. Tosaki, M. Bagchi, and S. C. Kothari, "Benefits of resveratrol in women's health," Drugs under Experimental and Clinical Research, vol. 27, no. 5-6, pp. 233248, 2001.

[22] J. Burns, T. Yokota, H. Ashihara, M. E. J. Lean, and A. Crozier, "Plant foods and herbal sources of resveratrol," Food Chemistry, vol. 50, no. 11, pp. 3337-3340, 2002.

[23] T. L. Parker, X. H. Wang, J. Pazmino, and N. J. Engeseth, "Antioxidant capacity and phenolic content of grapes, sundried raisins, and golden raisinsand their effect on ex vivo serum antioxidant capacity," Journal of Agricultural and Food Chemistry, vol. 55, no. 21, pp. 8472-8477, 2007.

[24] R. Soares and C. Costa, Eds., Oxidative Stress, Inflammations and Angiogenesis in the Metabolic Syndrome, Springer, Netherlands, 2009.

[25] F. Brisdelli, G. D'Andrea, and A. Bozzi, "Resveratrol: a natural polyphenol with multiple chemopreventive properties," Current Drug Metabolism, vol. 10, no. 6, pp. 530-546, 2009.

[26] K. R. Patel, E. Scott, V. A. Brown, A. J. Gescher, W. P. Steward, and K. Brown, "Clinical trials of resveratrol," Annals of the
New York Academy of Sciences, vol. 1215, no. 1, pp. 161-169, 2011.

[27] G. Mancia, G. De Backer, A. Dominiczak et al., "2007 guidelines for the management of arterial hypertension, the task force for the management of arterial hypertension of the European Society of Hypertension (ESH) and of the European Society of Cardiology (ESC)," Journal of Hypertension, vol. 25, no. 6, pp. 1105-1187, 2007.

[28] WHO/Europe, Body Mass Index-BMI, http://www.euro.who. int/en/health-topics/disease-prevention/nutrition/a-healthylifestyle/body-mass-index-bmi.

[29] American Diabetes Association (ADA) 2016 Guideline, Diabetes Management Guidelines, http://www.ndei.org/ ADA-diabetes-management-guidelines-in-patient-glycemiatargets-critically-ill.aspx.html.

[30] G. M. Sullivan and R. Feinn, "Using effect size-or why the P-value is not enough," Journal of Graduate Medical Education, vol. 4, no. 3, pp. 279-282, 2012.

[31] A. Bumbu, B. Pasca, D. M. Tit, S. Bungau, and G. Bumbu, "The effects of soy isoflavones and hormonal replacing therapy on the incidence and evolution of postmenopausal female urinary incontinence," Farmacia, vol. 64, no. 3, pp. 419-424, 2016.

[32] A. Carrizzo, A. Puca, A. Damato et al., "Resveratrol improves vascular function in patients with hypertension and dyslipidemia by modulating NO metabolism," Hypertension, vol. 62, no. 2, pp. 359-366, 2013.

[33] M. M. Sung, N. J. Byrne, I. M. Robertson et al., "Resveratrol improves exercise performance and skeletal muscle oxidative capacity in heart failure," American Journal of Physiology Heart and Circulatory Physiology, vol. 312, no. 4, pp. H842H853, 2017.

[34] C. H. Cottart, V. Nivet-Antoine, and J. L. Beaudeux, "Review of recent data on the metabolism, biological effects, and toxicity of resveratrol in humans," Molecular Nutrition \& Food Research, vol. 58, no. 1, pp. 7-21, 2014.

[35] L. M. Hung, J. K. Chen, S. S. Huang, R. S. Lee, and M. J. Su, "Cardioprotective effect of resveratrol, a natural antioxidant derived from grapes," Cardiovascular Research, vol. 47, no. 3, pp. 549-555, 2000.

[36] S. Gomez-Zorita, A. Fernandez-Quintela, A. Lasa, E. Hijona, L. Bujanda, and M. P. Portillo, "Effects of resveratrol on obesity-related inflammation markers in adipose tissue of genetically obese rats," Nutrition, vol. 29, no. 11-12, pp. 1374-1380, 2013.

[37] V. Ljubicic, M. Burt, J. A. Lunde, and B. J. Jasmin, "Resveratrol induces expression of the slow, oxidative phenotype in $\mathrm{mdx}$ mouse muscle together with enhanced activity of the SIRT1PGC-1 $\alpha$ axis," American Journal of Physiology-Cell Physiology, vol. 307, no. 1, pp. C66-C82, 2014.

[38] P. Rashid, J. Leonardi-Bee, and P. Bath, "Blood pressure reduction and secondary prevention of stroke and other vascular events, a systematic review," Stroke, vol. 34, no. 11, pp. 27412748, 2003.

[39] K. D. Flemming and R. Brown Jr., "Secondary prevention strategies in ischemic stroke: identification and optimal management of modifiable risk factors," Mayo Clinic Proceedings, vol. 79, no. 10, pp. 1330-1340, 2004.

[40] C. Sierra, A. Coca, and E. L. Schiffrin, "Vascular mechanisms in the pathogenesis of stroke," Current Hypertension Reports, vol. 13, no. 3, pp. 200-207, 2011. 
[41] P. Pacher, J. S. Beckman, and L. Liaudet, "Nitric oxide and peroxynitrite in health and disease," Physiological Reviews, vol. 87, no. 1, pp. 315-424, 2007.

[42] R. M. Touyz and E. L. Schiffrin, "Reactive oxygen species in vascular biology: implications in hypertension," Histochemistry and Cell Biology, vol. 122, no. 4, pp. 339-352, 2004.

[43] S. Czernichow, J. Blacher, and S. Hercberg, "Antioxidant vitamins and blood pressure," Current Hypertension Reports, vol. 6, no. 1, pp. 27-30, 2004.

[44] K. Fodor, D. M. Tit, S. Bungau, F. Dragan, and D. Gatea, “The evaluation of the effectiveness of resveratrol in blood pressure," Annals of Oradea University, Fascicle: Ecotoxicology, Animal Husbandry and Technologies for Food Industry, vol. 13, no. A, pp. 105-110, 2014.

[45] J. H. John, S. Ziebland, P. Yudkin, L. S. Roe, and H. A. W. Neil, "Effects of fruit and vegetable consumption on plasma antioxidant concentrations and blood pressure: a randomised controlled trial," The Lancet, vol. 359, no. 9322, pp. 1969-1974, 2002.

[46] J. A. Baur and D. A. Sinclair, "Therapeutic potential of resveratrol: the in vivo evidence," Nature Reviews Drug Discovery, vol. 5, no. 6, pp. 493-506, 2006.

[47] M. Theodotou, K. Fokianos, A. Mouzouridou et al., "The effect of resveratrol on hypertension: a clinical trial," Experimental and Therapeutic Medicine, vol. 13, no. 1, pp. 295-301, 2017.

[48] X. Cao, T. Luo, X. Luo, and Z. Tang, "Resveratrol prevents AngII-induced hypertension via AMPK activation and RhoA/ROCK suppression in mice," Hypertension Research, vol. 37, no. 9, pp. 803-810, 2014.

[49] A. Leiherer, A. Mündlein, and H. Drexel, "Phytochemicals and their impact on adipose tissue inflammation and diabetes," Vascular Pharmacology, vol. 58, no. 1-2, pp. 3-20, 2013.

[50] C. A. Baile, J. Y. Yang, S. Rayalam et al., "Effect of resveratrol on fat mobilization," Annals of the New York Academy of Sciences, vol. 1215, no. 1, pp. 40-47, 2011.

[51] J. Ahn, I. Cho, S. Kim, D. Kwon, and T. Ha, "Dietary resveratrol alters lipid metabolism-related gene expression of mice on an atherogenic diet," Journal of Hepatology, vol. 49, no. 6, pp. 1019-1028, 2008.

[52] M. Lagouge, C. Argmann, Z. Gerhart-Hines et al., "Resveratrol improves mitochondrial function and protects against metabolic disease by activating SIRT1 and PGC- $1 \alpha$," Cell, vol. 127, no. 6, pp. 1109-1122, 2006.

[53] A. Lasa, M. Schweigerb, P. Kotzbeck et al., "Resveratrol regulates lipolysis via adipose triglyceride lipase," The Journal of Nutritional Biochemistry, vol. 23, no. 4, pp. 379-384, 2012.

[54] J. A. Baur, K. J. Pearson, N. L. Price et al., "Resveratrol improves health and survival of mice on a high-calorie diet," Nature, vol. 444, no. 7117, pp. 337-342, 2006.

[55] A. Dal-Pan, J. Terrien, F. Pifferi et al., "Caloric restriction or resveratrol supplementation and ageing in a non-human primate: first-year outcome of the RESTRIKAL study in Microcebus murinus," Age, vol. 33, no. 1, pp. 15-31, 2010.

[56] A. Dal-Pan, S. Blanc, and F. Aujard, "Resveratrol suppresses body mass gain in a seasonal non-human primate model of obesity," BMC Physiology, vol. 10, no. 1, p. 11, 2010.

[57] O. R. Oyenihi, A. B. Oyenihi, A. A. Adeyanju, and O. O. Oguntibeju, "Antidiabetic effects of resveratrol: the way forward in its clinical utility," Journal of Diabetes Research, vol. 2016, Article ID 9737483, 14 pages, 2016.
[58] T. Szkudelski and K. Szkudelska, "Resveratrol and diabetes: from animal to human studies," Biochimica et Biophysica Acta (BBA) - Molecular Basis of Disease, vol. 1852, no. 6, pp. 11451154, 2015.

[59] B. Yi and N. Maeda, " $\alpha$ - lipoic acid prevents the increase in atherosclerosis induced by diabetes in apolipoprotein Edeficient mice fed high-fat/low-cholesterol diet," Diabetes, vol. 55, no. 8, pp. 2238-2244, 2006.

[60] P. Brasnyo, G. A. Molnar, M. Mohas et al., "Resveratrol improves insulin sensitivity, reduces oxidative stress and activates the Akt pathway in type 2 diabetic patients," British Journal of Nutrition, vol. 106, no. 03, pp. 383-389, 2011.

[61] O. Vang and D. K. Das, "Resveratrol and health," Annals of the New York Academy of Sciences, vol. 1215, no. 8, pp. 1-7, 2011.

[62] N. L. Price, A. P. Gomes, A. J. Ling et al., "SIRT1 is required for AMPK activation and the beneficial effects of resveratrol on mitochondrial function," Cell Metabolism, vol. 15, no. 5, pp. 675-690, 2012. 


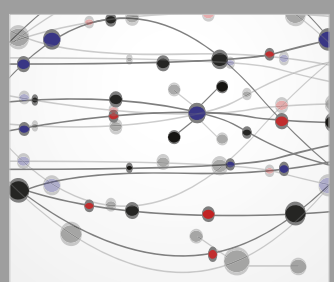

The Scientific World Journal
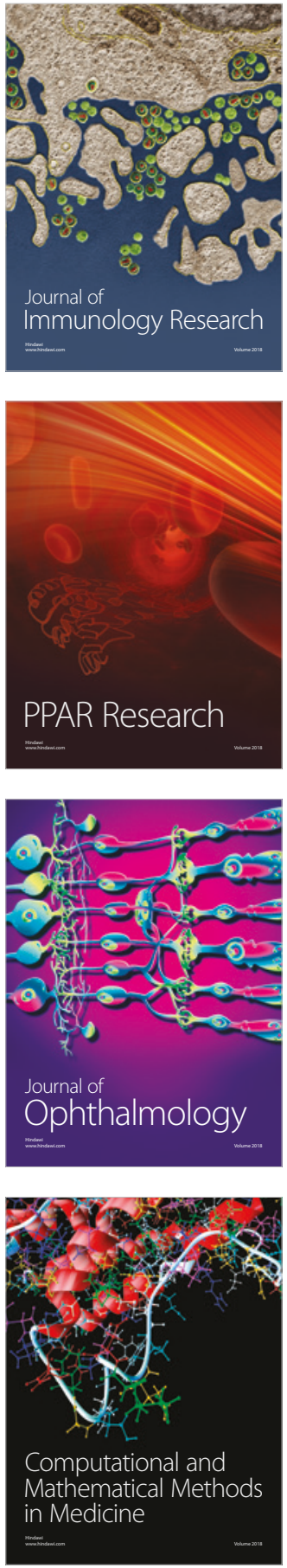

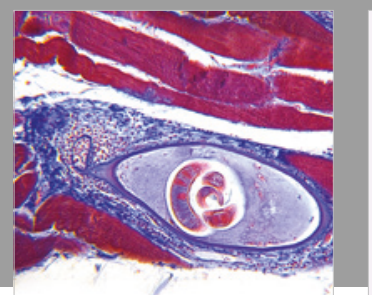

Gastroenterology Research and Practice

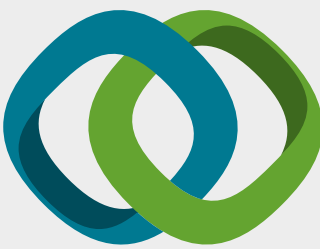

\section{Hindawi}

Submit your manuscripts at

www.hindawi.com
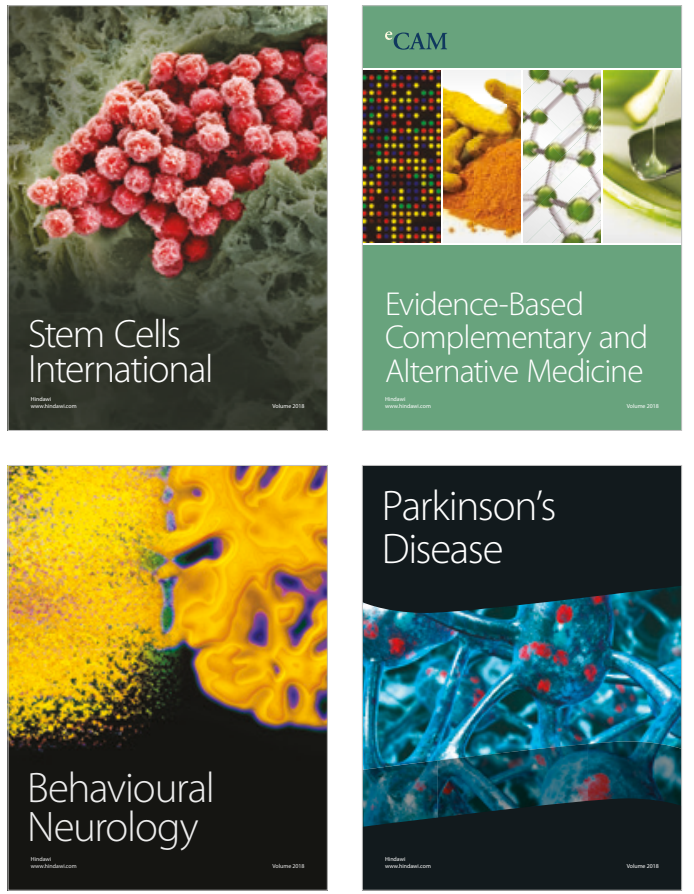

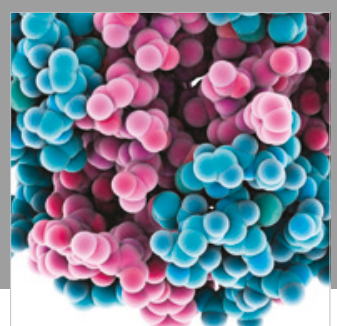

ournal of

Diabetes Research

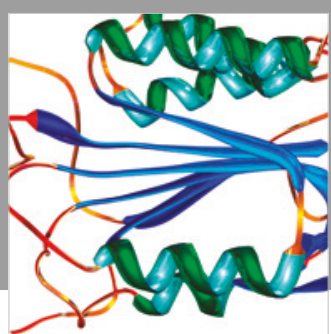

Disease Markers
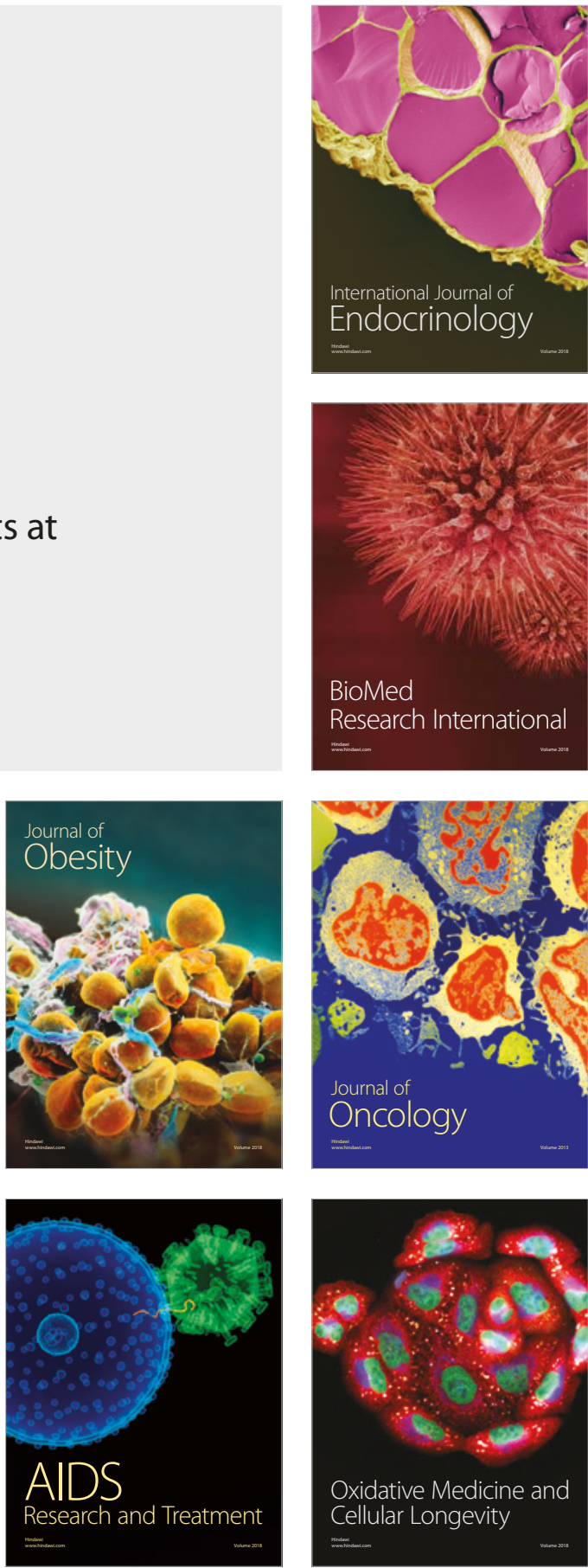